\title{
Fighting Against Obesity and Overweight: Approach to Design a New Service in Nutrition Education
}

\author{
Marisela Rodriguez, Daniela Charvel \\ Quality and Manufacturing Center, Tecnologico de Monterrey, Monterrey, Mexico. \\ Email: marisrod@itesm.mx, danielacharvelk@hotmail.com
}

Received December $5^{\text {th }}, 2012$; revised January $8^{\text {th }}, 2013$; accepted January $20^{\text {th }}, 2013$

\begin{abstract}
Overweight and obesity (O\&O) are a global public health problem, which many scientists have named as the XXI century epidemic. Since the 80 's decade, the O\&O world prevalence has increased both in children and adults, and Mexico is among the highest. Under this context, the main goal of this research is to develop a business model based on a service of nutritional education as a way to fight against O\&O. This research proposes a new model founded on a strategic combination of Service Design and Competitive Intelligence methodologies. The aim is to generate a unique and innovative service tailored to customer needs.
\end{abstract}

Keywords: Innovation; Obesity; Overweight; Service Design; Nutrition Education; Competitive Intelligence

\section{Introduction}

Overweight and obesity (O\&O) represent a strong public health issue, in fact they are considered as the $21^{\text {st }}$ century epidemic due to its magnitude, its growth rate, and the negative effect it has on the population. The World Health Organization states that 2.6 million people die each year as a result of overweight and obesity [1].

According to the Organization for Economic Cooperation and Development, Mexico ranks second place in overweight and obesity, in both adults and children, with prevalence, among adults, of overweight at $39.5 \%$, and of obesity at $31.7 \%$ [2]. These means that approximately 7 out of 10 adults suffer from O\&O. On the other hand, statistics of child population have shown that 1 out of 3 children suffers from overweight or obesity resulting in 4.5 million children between 5 and 11 years old [3]. As we can see, future generations could face serious metabolism problems and irreversible diseases.

The control and solution of O\&O constitutes a real challenge for all the countries; despite the many efforts to eradicate it, this problem has been increasing, threatening the welfare of people and development of society. Under this context, the main goal of this research is to develop a business model based on nutritional education. That's why a service-business opportunity consisting of teaching to control and/or lose weight is explored.

The model was developed through a methodology based on the combination of Service Design and Competitive Intelligence tools to provide a nutrition service in the North of Mexico (Monterrey and San Pedro cities).

\section{Overweight and Obesity in Mexico}

In 2000, the Mexican Official Norm for Integral Treatment for Obesity and Overweight defined O\&O as:

"Chronic disease characterized by the excess of fat tissue in an organism. It comes with metabolic alterations that produce disorders that deteriorate health, associated in most of cases with endocrine, cardiovascular and orthopedic pathology. It is related to biological, socio-cultural and psychological factors" [4].

Body Mass Index (BMI) is a simple index of weightfor-height that is commonly used to classify underweight, overweight and obesity in adults. It is defined as the weight in kilograms divided by the square of the height in meters $\left(\mathrm{kg} / \mathrm{m}^{2}\right)$. People are considered with overweight when their BMI ranges between 25 and 29.9. In the case that BMI is equal or superior to 30 , people are diagnosed with obesity [5].

The ENSANUT (National Health and Nutrition Survey) is in charge of getting information regarding Mexican population health, including adult and children nutrition status, prevalence of chronic diseases, and quality of health services. The ENSANUT in 2006, revealed shocking statistics about nutrition disorders: the prevalence of O\&O in adults is at $71.9 \%$ in women and at $66.7 \%$ in men [6].

In the last years, consumption of industrialized food has increased; the access to this kind of food is growing in comparison to healthy food. To cite an example, Mexico is the main consumer of carbonated beverages and instant soups worldwide [7]. In fact, vegetables, meat, 
and dairy products consumption have decreased substantially in the past 20 years as we can see in the next graphic (Figure 1).

The transition of rural population to urban zones coincides with O\&O growth. During the first half of the $20^{\text {th }}$ century the rural population of the country was $75 \%$ to $80 \%$, while the urban population was $20 \%$ to $25 \%$. For the second half of the century, this situation changed leading to a percentage of rural population of only $20 \%$ to $25 \%$. This resulted in a strong nutritional change and in some cases an augmentation of sedentary human activities [8].

Obesity condition is mainly the result of high-energy food consumption plus physical inactivity. According to ENJUVE (National Survey on Youth), 60\% of the persons between 12 and 29 years old do not practice physical activity [9]. This is an alarming fact since most of the Mexican population is young. The problem is complex as sedentary lifestyle in this country is frequently a consequence of economical crisis, deficiencies in appropriate facilities, long time invested in transportation, insecurity and ignorance about the benefits of exercise, etc.

Additionally, we currently live on a world where publicity has a great influence to increase the consumption of industrialized food. On the other hand, there is some kind of refuse from some big food chains to show the consequences of fast food in excess. Another issue emerges when people choose faster ways to lose weight, for example consuming "miracle" products or doing magazine diets. This only makes them risk their lives since usually they do not have medical supervision while following their diet.

We are convinced that one way to face O\&O and consequences of this is through nutrition education, as the renowned bariatric doctor, Tom Hopkins pointed, nutriation education is an area that can make a big difference in health [10]. People should not only know their health condition (for example, when they go to the doctor) but they also should acquire enough knowledge about positive and negative effects of the food they ingest not only to correct bad habits but also to prevent bad consequences.

Nutrition education is defined as a combination of learning strategies to induce adoption of feed habits that contribute to health and well-being [11]. Nutrition education should continuously incorporate new scientific knowledge, with appropriate messages according to different age groups [12]. There are some government programs on nutrition education; however it is still an area of opportunity that Mexico faces. As we have seen from precedent information this is a real problem not only for the present but also for the future. This is the reason why we decided to develop a model based on nutrition education. In order to accomplish this task, it was necessary to explore Service Design tools; in particular, we selected the approach from Moritz [13] as we found it more suitable to apply it under Mexico's conditions.

Service Design is an area that consists on innovating or improving existing services to make them more useful, usable and desirable for clients. Services consist of numerous components, usually intangible entities, but have a combination of processes, skills and applied resources [14]. As Moritz points, Service Design is a discipline where shape and functionality are established from customer perspective. Generally, the figurative production and consumption of a service occurs simultaneously, so the challenge is to create a real link with the customer at the moment. In the case of health sector the concept of

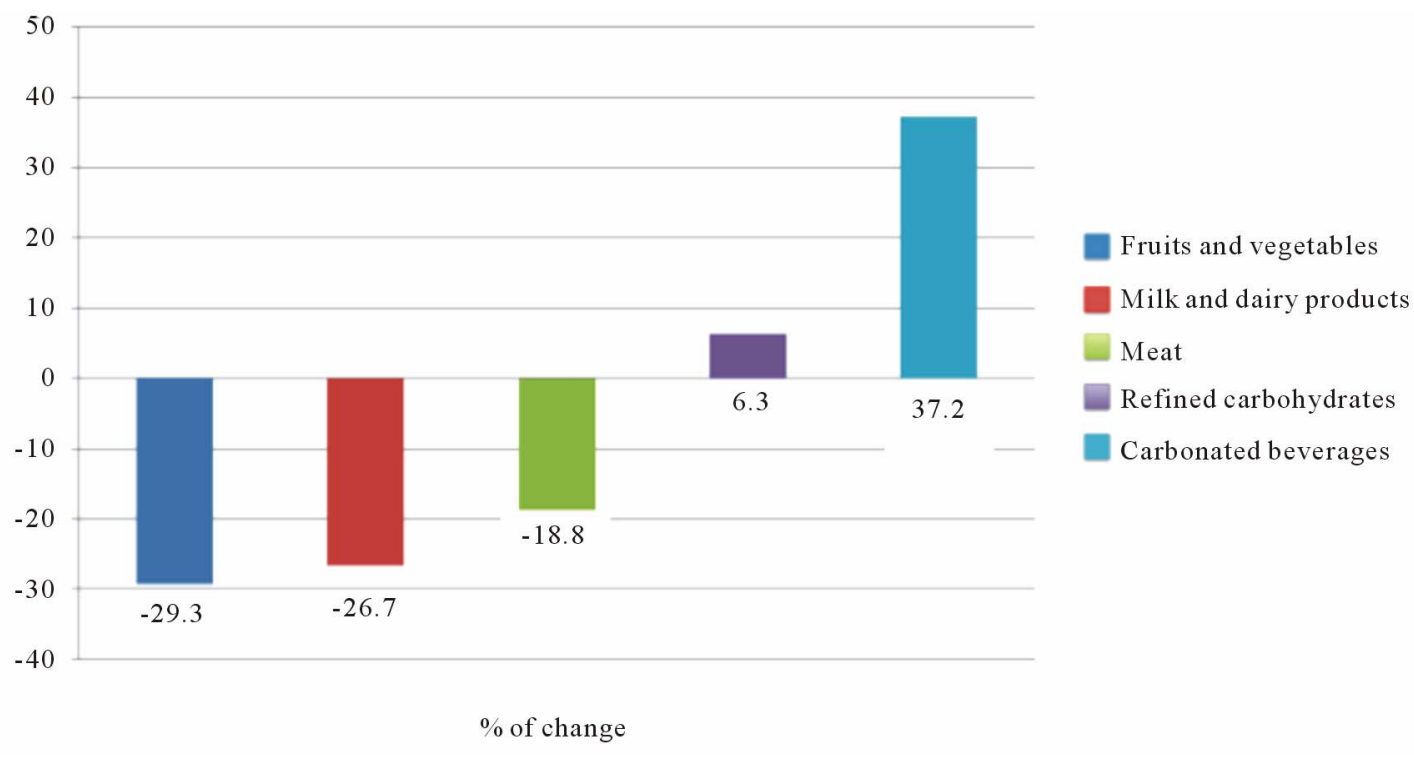

Figure 1. Percentage change in the pattern of food purchases in Mexico [7]. 
“focusing on patient welfare” becomes essential [13].

Moritz Service Design tool is based in 6 categories: understanding, thinking, generating, filtering, explaining, realizing. They are developed through a multidisciplinary process where integration and communication of areas such as product design, brand design, marketing research, interior design, communication planning and management processes, are implemented. Some of these activeties require a formal research process of monitoring the environment, for this purpose we selected the Competitive Intelligence methodology.

Competitive Intelligence (CI) is a formal process where management team assesses the evolution of the industry and its capabilities, just as the behavior of potential competitors to develop and maintain a competitive advantage [15]. The CI process is shown in the next figure (Figure 2).

This area aims to help executives to make better decisions, especially those related to the market, product design, research and development, and activities involved in innovation [16]. The importance of CI to service design lies in the possibility to anticipate the changes that occur in the business environment supporting the decision-making process.

\section{Methodology}

We consider that an appropriate synergy of precedent tools: Service Design [13] and Competitive Intelligence [16] could contribute significantly to the strategic planning of innovations, whether are services, goods or a combination of them. For the purpose of this research, we departed from both approaches and developed a Methodology we called as: Service Design for Innovation and Competitiveness.

This methodology is composed by 6 stages:

1) Discovery and learning.

Its goal is to identify a new business opportunity by analyzing the market and by learning from the potential customers.

2) Competitive intelligence cycle.

It includes the collection and analysis of information from the environment using primary (field research) and secondary (documental) sources with the aim to detect key elements for designing.

3) Concept development.

Based on the previous inputs, different alternatives of the service involved are developed and as a result a portfolio is built. The main focus of this stage should be to try to generate a unique experience during the interaction user-service.

4) Concept selection and trial.

Considering previous alternatives identified, selection of the final concept is made considering a niche market, customer requirements, competitors, budget, activities and people involved. After this, a first trial of the service is made in order to identify some areas that could need change.

5) Evaluation.

Service efficiency and client satisfaction is achieved with the final concept previously selected and corrected, they could be evaluated by the ISO-International Organization for Standardization 9421-11 (1998).

6) Implementation.

In this final step application of the service becomes a reality; a business model regularly is developed together with the project to specify how the service should work.

Each step of the methodology is illustrated in the next figure (Figure 3).

\section{Application}

\subsection{Discovery and Learning}

This stage started by applying surveys in the market niche selected which was high to medium socioeconomic status. Strategic places in the cities of Monterrey and San Pedro, Mexico were chosen, as this was the target place

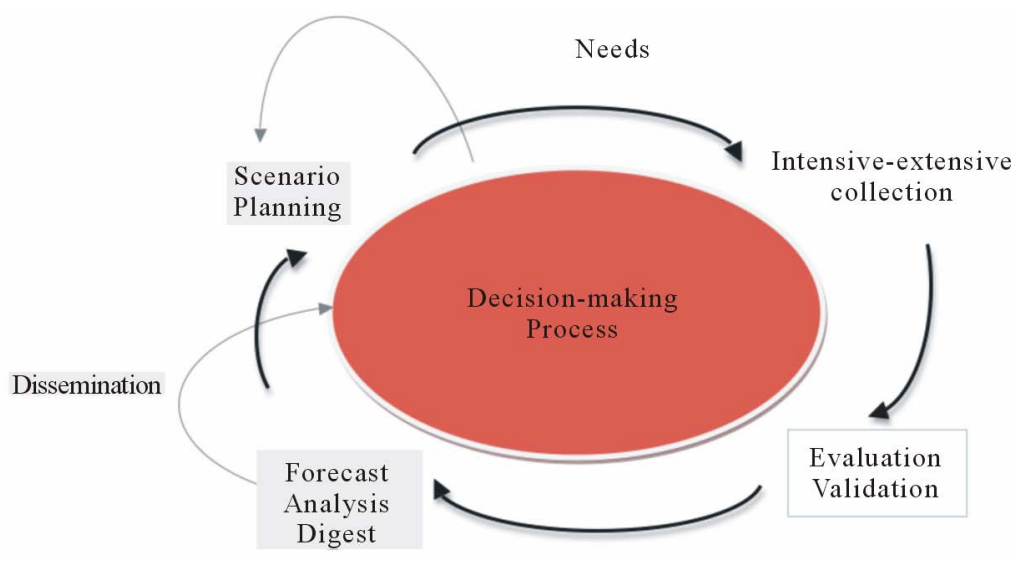

Figure 2. Competitive intelligence process [15]. 


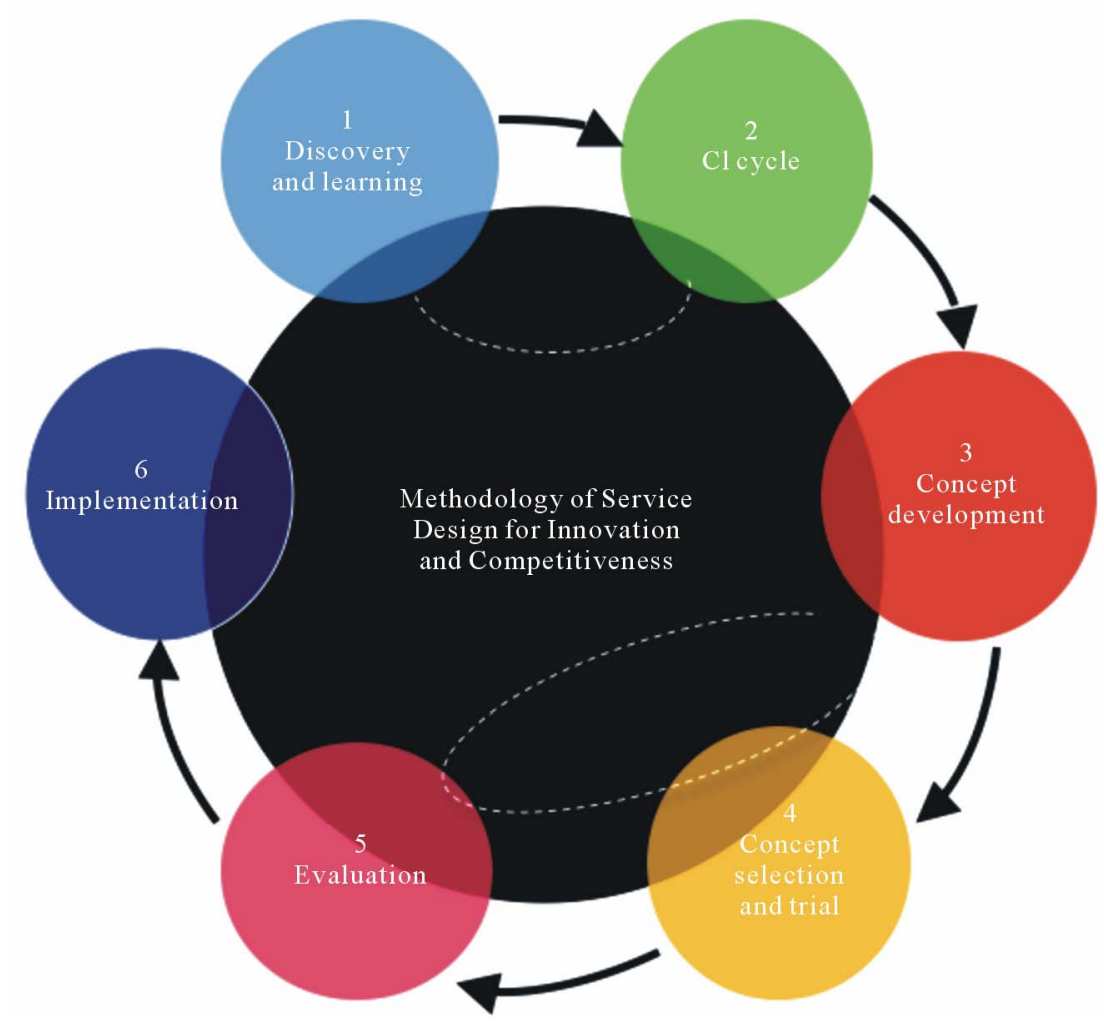

Figure 3. Methodology of service design for innovation and competitiveness.

for further implementation.

Results obtained show the following customer needs listed in order of importance:

- Learn to eat right;

- Get the service in accessible prices;

- Obtain quick and lasting results on diets;

- Be served by kind and well-trained people;

- Facilities with attractive presentation;

- Have a comfortable place.

A research about the main providers of nutrition services (clinics, schools...) was also developed in this stage. Country lead experts in nutrition were interviewed and the results were considered in the next stages.

\subsection{Competitive Intelligence Cycle}

Some of the activities involved in this methodology were previously developed; for example those concerning planning of activities, information sources identification and gathering. Aspects like the exploration of service processes; interface design and a virtual prototype of the space architecture were also analyzed in this phase. One of the most relevant sources of information was Euromonitor International Ltd. A database with information of market reports, reference books, company profiles, current market data, and market forecasts. Internet in general was useful in identifying competitors as well as products to lose weight that are sold in Mexico, mostly in convenience stores. Also a research field was developed. Globally, the sources of information considered in this research were:

- Primary. Interviews with nutrition experts, clients, competitors and suppliers.

- Secondary. Journals, reports, norms, bulletins and blogs.

At the end of this stage the corresponding analysis established that:

1) The growth rate of weight management products of $16 \%$ in current value terms in 2011 was double the previous year's increase. There is a high demand of weight loss products and services in Mexico as a consequence of the increasing of O\&O [17].

2) There is more awareness campaigns regarding the risks overweight and obesity involves, causing people to want to adopt more active and healthy lifestyles [17].

3) International companies have a bigger share in this market; so, prices of weight control products in Mexico have sustained increases especially as they have imported ingredients [18].

\subsection{Concept Development}

In order to create unique experiences with the service proposed, a tool named Storyboard was used; this tool is related with the identification of the feeling produced in a person when interacting with a set of pictures or images 
organized as a story. As Morgan establishes, this is a powerful tool of communicating ideas to the potential customer when we try to find possible acceptation of a process or a product [19].

Under this context storyboard allowed us to determine the kind of experience generated with a virtual prototype of the nutritional service proposed. This evaluation considers from the facilities (colors, illumination, furniture and logistic), the type of patient valuation and consecutive tracking to the payment method. For this purpose different concepts were evaluated by potential customers and experts from the nutritional area.

Finally, the concept generated was ENUA (Advanced Nutritional Education) which is a service that aims to provide a new way to take care from the nutritional perspective; a service where the customer not only could get a valuation of his nutritional level and a corresponding diet, but also where he could learn about nutrition and have continuous supervision during a formal process of nutritional care. Moreover, this proposal intends to make ENUA a service focused in the welfare of the customer through personal attention tailored to specific needs. Under this notion, the customers are free to elaborate a schedule program according to their specific needs including their lifestyle.

\subsection{Concept Selection and Trial}

Different concepts were developed using information from the previous stages: Competitive Intelligence and from the Storyboard one. Finally the most relevant was one that could include additional services like cooking lessons (virtual and face-to-face), fitness boot camp and information on mobile device. This implies to have not only people involved in nutrition but also in sport activities. In particular, experts interviewed highlighted:

- Add more relevance to the fact of providing support from a multidisciplinary and high trained group than to the image design.

- Implement a tracking supervision. It is important to assess the impact that the program could have in the lifestyle of the customer; receive feedback about the service and make proper adjustments.

During the concept trial task, 15 potential customers were randomly selected from the market niche. They were interviewed with basic questions (age, occupation, scholarly, etc.) to know if they would like this kind of service proposed. Main results were:

- $10 \%$ of the participants admitted that they would surely use the service. $80 \%$ admitted that they would probably use the service.

- The aspects they were more interested in were to have a fitness boot camp, the cooking lessons and nutrition courses.
- The pricing rank goes from \$936 USD to \$1248 USD [20]. This price represents the total for the six-month program, which includes the fitness boot camp, ENUA classes, cooking lessons, multidisciplinary group guidance, and website access.

- Finally, they suggested expanding the market to other cities of the country.

\subsection{Evaluation}

To accomplish this task we established the following quantitative and qualitative indicators:

Quantitative (basic ones):

- Number of customers in the program;

- Number of patients per ENUA class;

- Number of patients per cooking lesson;

- Website visit counter.

Qualitative:

- Complaints. We propose to have a formal system that registers, categorizes and follows complaints from the customers. The most important would be not only identify service deficiencies but also implement corrective actions. We suggest that this system has a combination between personal face-to face interaction in the facilities and a virtual communication using the webpage of ENUA (customer could have the possibility to decide what way is better for him or her).

- Regular satisfaction surveys. We recommend a continuous monitoring by using the webpage to interview customers.

\subsection{Implementation}

While final implementation of the service proposed has not been done up to now as it will be at the discretion of the principal author of this research Ms. Daniela Charvel; key issues to be considered to develop this phase were identified according to Osterwalder and Pigneur proposal [21]. Based on this approach nine elements should be taken into consideration and in the service designed are as follow:

1) Customer segment. High to medium socioeconomic status of the North of Mexico, in particular Monterrey and San Pedro cities.

2) Value proposition. A program that intends to be a global and personalized service in function of customer specific needs. Three main value propositions were established:

- Teaching model. The customer learns about nutrition and cooking under the supervision of a specialist team.

- ENUA Integral Program. It consists on nutrition valuation and consecutive advice, cooking lessons and a continuous guidance from a multidisciplinary group composed by a nutritionist, physical trainer, psy- 
chologist, image designer and aesthetic medicine specialist.

- Fitness Boot Camp. Where patients could exercise following a specific guideline.

3) Channels. Previous value propositions will be offered to customers with the support of a sales force team including promotion by social media.

4) Customer relationship. With the purpose of establishing long lasting relationships with the customers this service should:

- Be user-focused design.

- Maintain a continuous co-innovation with customers after initial implementation.

- Track complaints and act in consequence.

5) Revenue streams. A financial analysis including ROI, NPV, etc. should be done in order to assess feasibility of service proposed. For this task it is required to define previously with detail all elements involved in the final implementation, for example: place, facilities, equipment, number and type of people to hire, and characteristics of the service itself including subscription. With reference to this last point the analysis from the market suggested:

- Four-month subscription program. We suggest a monthly payment which would include: initial valuation, nutrition advice, cooking classes, supervision and website access;

- Six-month subscription program. This program would include everything in the previous program plus the Fitness Boot Camp.

6) Key resources. It includes tangible and intangible ones.

- The location. In the North of Mexico, in Monterrey and San Pedro cities which are the municipalities with the highest GDP of the country;

- The Internet platform. A tool where customers can pay for the service, access to specialized information and share views with an ENUA Community;

- The Multidisciplinary team;

- The brand. In this aspect, a brand and logo was developed, for confidential raisons it is not showed in this paper as they are in process of legal protection. The final aim of this task is to have an attractive way for customer to identify the service.

7) Key activities. To execute during the implementation for example:

- Monitor rate of current and new subscriptions;

- Supervise complaints;

- Keeps the staff trained;

- Pursue innovation continuously.

8) Key partners. Those externals and from the organization.

- Customers;

- Suppliers;
- Affiliations from the multidisciplinary group (associations, communities);

- People in charge of others Fitness Boot Camp spaces. 9) Cost structure. Includes tangibles and intangibles, for example:

- Advertising costs;

- Location rental;

- Camping site rental;

- Purchase or rental of equipment;

- Purchase of uniforms and all accessories required to provide the service;

- Internet platform design and maintenance;

- Employees’ salaries.

\section{Conclusions}

The present research proposes a model integrating two tools: Service Design by Moritz [13] and Competitive Intelligence [16] as a result the Methodology of Service Design for Innovation and Competitiveness was created.

This methodology aims to produce a unique and meaningful service by a design process that involves strategic activities to uncover customer needs. It is important to remark that only the first stages were implemented (until the concept generation and selection), further stages will be implemented in the future.

During execution of the proposed model, some barriers were necessary to overcome for example, proper identification of the requirements of potential customers; competitor analysis; generation of a portfolio of design concepts and process and analysis of primary and secondary information to get relevant insights. At the end, we are convinced that the proposed model could offer a new way to undertake a new service design.

\section{Acknowledgements}

We thank Mr. Alejandro Palacios and Tecnologico de Monterrey for the help and support received.

\section{REFERENCES}

[1] World Health Organization WHO, "Global Strategy on Diet, Physical Activity and Health,” 2012. http://www.who.int/dietphysicalactivity/childhood_conse quences/en/index.html

[2] Organization for Economic Cooperation and Development OECD, “Obesity Rate in Adult Population,” 2011. http://www.oecd.org/centrodemexico/medios/30elindiced eobesidadenmexico.htm

[3] Ministry of Health, "National Agreement for Nutritional Health,” 2010.

http://www.promocion.salud.gob.mx/dgps/descargas1/pro gramas/Acuerdo\%20Original\%20con\%20creditos\%2015 \%20feb\%2010.pdf

[4] Ministry of Health, "Mexican Official Norm NOM-008- 
SSA3-2010 for the integral treatment of overweight and obesity,” 2005.

http://web.ssaver.gob.mx/obesidad/files/2012/02/norma-o fi-

cial-mexicana-nom-008-ssa3-2010-PARA-EL-TRATAM

IENTO-INTEGRAL-DEL-SOBREPESO-Y-LA-OBESID AD.pdf

[5] World Health Organization WHO, "BMI Classification," 2012.

http://apps.who.int/bmi/index.jsp?introPage=intro_3.html

[6] Ministry of Health, "National Health and Nutrition Survey ENSANUT," 2006. http://www.insp.mx/images/stories/ENSANUT/Docs/Ens anut2006.pdf

[7] Ministry of Health, “Technical Basis of National Agreement for Nutritional Health. Strategy against Overweight and Obesity,” 2010.

http://portal.salud.gob.mx/descargas/pdf/ANSA_bases_te cnicas.pdf

[8] J. González, “Obesity: A public Health Problem in Mexico,” Nutrición Clínica, Vol. 5, No. 4, 2002, pp. 213-218.

[9] Mexican Institute of Youth, "National Survey on Youth ENJUVE,” 2005.

http://sic.conaculta.gob.mx/centrodoc_documentos/292.p df.

[10] T. Hopkins, "Bariatric Physician,” Managed Healthcare Executive, Vol. 20, No. 8, 2010, pp. 19-19.

[11] I. Contento, "Nutrition Education: Linking Theory, Research, and Practice,” Jones \& Bartlett Publishers, Sudbury, 2007.

[12] M. Velázquez, S. Rodríguez and M. Hernández, "Importance of Nutrition Education in Elderly People," $\mathrm{Nu}$ trición Clínica, Vol. 6, No. 1, 2003, pp. 84-88.

[13] S. Moritz, "Service Design: Practical Access to an Evolv- ing Field,” 2005.

http://stefan-moritz.com/_files/Practical\%20Access\%20to \%20Service\%20Design.pdf

[14] American Marketing Association-AMA, "Service Definition,” 2012.

http://www.marketingpower.com/_layouts/Dictionary.asp $\mathrm{x}$ ?dLetter $=\mathrm{S}$.

[15] R. P. Mignogna, “Competitive Intelligence: A New Addition to Your Technology Transfer Toolkit,” Proceedings of the 1997 Technology Transfer Society Annual Conference, Denver, 21-23 July 1997.

[16] M. Rodriguez, “Technical Intelligence: Building Technology Maps to Identify Recent Areas of Research on Advanced Materials and Sintering,” Ph.D. Dissertation, Polytechnic University of Catalonia, Barcelona, 1999.

[17] Euromonitor Passport GMID, "Weight Management in Mexico: Trends,” 2012.

http://www.euromonitor.com/passport-gmid

[18] Euromonitor Passport GMID, "Weight Management in Mexico: Company Shares by Global Brand Owner,” 2012. http://www.euromonitor.com/passport-gmid

[19] S. Morgan and R. Dennehy, "The Power of Organizational Storytelling: A Management Development Perspective,” Journal of Management Development, Vol. 16, No. 7, 1997, pp. 494-501. doi:10.1108/02621719710169585

[20] Bank of Mexico, "Foreign Exchange Markets—Exchange Rates,” 2012. http://www.banxico.org.mx/portal-mercado-cambiario/for eign-exchange-markets--exc.html

[21] A. Osterwalder and Y. Pigneur, "Business Model Generation: A Handbook for Visionaries, Game Changers, and Challengers,” John Wiley \& Sons, Hoboken, 2010. 